\title{
Investigation of PMU Response to Leap Second: 2015
}

\author{
Allen Goldstein \\ Dhananjay Anand \\ Ya-Shian Li-Baboud
}

This publication is available free of charge from: http://dx.doi.org/10.6028/NIST.IR.8077

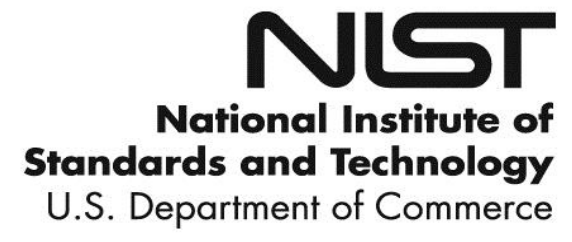




\title{
Investigation of PMU Response to Leap Second: 2015
}

\author{
Allen Goldstein \\ Quantum Measurement Division \\ Physical Measurement Laboratory \\ Dhananjay Anand \\ Ya-Shian Li-Baboud \\ Software and Systems Division \\ Information Technology Laboratory
}

This publication is available free of charge from: http://dx.doi.org/10.6028/NIST.IR.8077

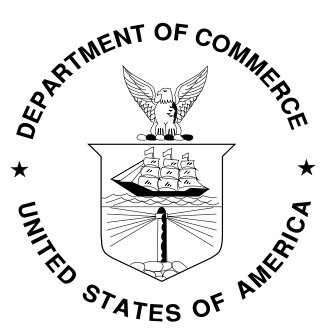

U.S. Department of Commerce

Penny Pritzker, Secretary

National Institute of Standards and Technology Willie May, Under Secretary of Commerce for Standards and Technology 


\section{Overview}

International Atomic Time (TAI) is a globally agreed upon time scale. TAI is a continuous count of elapsed seconds since the beginning of 1958, including some small, agreed-upon adjustments as time-keeping technology became more precise over the years. TAI time is based on ensembles of atomic clocks around the world which are periodically compared with each other to form a continuous count of elapsed seconds. The rotation of the earth is not constant. By agreement, Coordinated Universal Time (UTC) is kept synchronized to within 0.9 seconds of the actual rotation of the earth; this is implemented by occasionally adding or subtracting a "leap second" to UTC at a globally agreed upon instant of time.

Between 22:30:00 June 30, 2015 and 00:30:00 July 2, 2015 UTC, the National Institute of Standards and Technology (NIST) tested 8 Phasor Measurement Units (PMUs) to investigate their response to the leap second adjustment to UTC which occurred following 23:59:59 UTC on June 30, 2015. At this time, the offset between TAI and UTC time incremented by 1 second from 35 seconds to 36 seconds. The UTC Time of Day (TOD) during an added leap second can be represented by either repeating 29:59:59 or inserting 23:59:60 for one second. This report shall represent the TOD during the leap second as 23:59:60

NIST tested 8 PMU models, 4 of which received their timing signal from GPS and 4 of which received their timing from the Inter-Range Instrumentation Group (IRIG) Standard 200 signal with Institute for Electrical and Electronics Engineers (IEEE) Std. 1344 ${ }^{\mathrm{TM}}-1995$ specified use of the IRIG control bits [1] [2]. The IRIG generator received its timing signal from the Global Positioning System (GPS). The IRIG signal carried UTC time (local offset $=0$ ) and the IEEE 1344 parity was even. Parity is mentioned here because there is an ambiguity concerning parity in the IEEE synchrophasor standards [1] [3] [4]. Also, while the GPS standard does not specify the time of day behavior during leap second (repeating the last second or adding an additional second), the IEEE 1344 standard states that the time of day should add an additional second, representing the inserted leap second as 23:59:60.

All PMUs were configured to report their synchrophasors using IEEE Std. C37.118.2 ${ }^{\mathrm{TM}}-2011$ compliant data transmission protocol [3]. The 8 PMUs are identified in this report by their PMU ID number from 1 to 8 . All PMUs except for PMU ID 2 were configured to output at 60 frames per second. PMU ID 2 output at 30 frames per second.

All PMUs were configured to compute phasors for a nominal $60 \mathrm{~Hz}$ balanced 3-phase analog voltage input at 70 Volts RMS and 3-phase current input at 1 Ampere RMS. The reported phase of a synchrophasor rotates with frequency relative to the nominal frequency. If the input signal frequency were equal to the nominal frequency, the reported phases would not change from report to report. The input voltage and current signal frequency for the leap second test was set to $59.9 \mathrm{~Hz}$ to induce an apparent 36 degrees/s rotation of the computed phasor to allow for realizations of phase error should the timestamps become erroneous.

The results of the leap second testing show the IRIG output from the GPS receiver did not conform to IEEE 1344. The Leap Second Pending bit was set and cleared one second too early, the binary coded decimal (BCD) time of day repeated the time 23:59:59 rather than progressing to 23:59:60 before rolling over to 00:00:00, and the straight binary seconds (SBS) repeated the last count of the day rather than proceeding to an additional count before rolling over to 0 . There were four PMUs which received their timing information from IRIG and four received their timing information from GPS antenna. None of the 8 PMUs remained synchronized with UTC during the leap second and demonstrated that there would be missing data and errors in the synchrophasor data due to incorrect Second of Century (SOC) in the report timestamps. The investigation also demonstrates how timing errors due to the leap second could also manifest as phase errors if the power system frequency is not exactly nominal. The details of the handling of the leap second as prescribed by IEEE Std. C37.118.2 $2^{\mathrm{TM}}-2011$ as well as the actual responses of the 8 PMUs are given in section 4.

\section{C37.118.2-2011 specified handling of leap second}

According to IEEE Std. C37.118.2 $2^{\mathrm{TM}}-2011$ Clause 6.2.2: Time and Message Time Quality, the most significant byte of the 32-bit Fraction of Second (FRACSEC) field in all PMU frame types is used as an 8-bit message time quality flag. The definition for this flag is in C37.118.2 Table 3, shown below in Figure 1: 
Table 3-Time quality flag bit definitions

\begin{tabular}{|c|l|}
\hline Bit \# & \multicolumn{1}{|c|}{ Description } \\
\hline 7 & Reserved \\
\hline 6 & Leap Second Direction-0 for add, 1 for delete \\
\hline 5 & $\begin{array}{l}\text { Leap Second Occurred-set in the first second after the leap second occurs and remains set } \\
\text { for } 24 \mathrm{~h}\end{array}$ \\
\hline 4 & $\begin{array}{l}\text { Leap Second Pending-shall be set not more than 60 s nor less than 1 s before a leap } \\
\text { second occurs, and cleared in the second after the leap second occurs }\end{array}$ \\
\hline $3-0$ & Message Time Quality indicator code-see Table 4. \\
\hline
\end{tabular}

Figure 1: C37.118.2-2011 Table 3

IEEE Std. C37.118.2 $2^{\mathrm{TM}}-2011$ Clause 6.2.3 Leap Second Bit Timing Examples shows an example of how the time count and leap second should appear for both a positive (added) and negative (deleted) leap second. No negative leap second has ever occurred, so the table below shows only an example of the positive leap second.

Table 1 has been paraphrased from the example of C37.118.2 ${ }^{\mathrm{TM}}-2011$ Clause 6.2.3. The Second of Century (SOC) time of the leap second has been updated to 1435708799, which is the SOC of the leap second on June 302015 , at 23:59:59 UTC. The SOC is the number of seconds which have elapsed since 00:00:00 UTC on January 1, 1970 not including the leap seconds that have occurred since then. Time of Day (TOD) in this example is incremented from 23:59:59 to 23:59:60 at the leap second. The black bars between rows indicate continuous elapsed time between the table entries. Some editorial changes were made to the comments in the table for clarity.

Table 1: Example of SOC and time quality bits around leap second

\begin{tabular}{|c|c|c|c|c|c|}
\hline SOC Time & Time of day & Direction & Occurred & Pending & Comments \\
\hline 1435708729 & $23: 58: 59$ & $\mathrm{X}$ & & & Direction bit any state before pending \\
\hline 1435708730 & $23: 59: 00$ & 0 & 0 & 1 & Pending bit can be set no earlier than here \\
\hline 1435708731 & 23:59:01 & 0 & 0 & 1 & \\
\hline 1435708798 & $23: 59: 58$ & 0 & 0 & 1 & \\
\hline 1435708799 & $23: 59: 59$ & 0 & 0 & 1 & Pending and direction bits shall be set no later than here \\
\hline 1435708799 & $23: 59: 60$ & 0 & 1 & 0 & Leap second occurs here \\
\hline 1435708800 & 00:00:00 & 0 & 1 & 0 & Occurred and direction bits remain set \\
\hline 1435708801 & 00:00:01 & 0 & 1 & 0 & \\
\hline 1435795199 & 23:59:59 & 0 & 1 & 0 & \\
\hline 1435795200 & 00:00:00 & $\mathrm{X}$ & 0 & 0 & Occurred bit must be cleared no later than here \\
\hline
\end{tabular}

Note that the PMU should repeat SOC Time 1435708799. If this does not occur, then the PMU timestamp will remain one second ahead of UTC time until something happens to reset the timestamp to the correct UTC time. This document will refer to the repeated SOC at the leap second as the LS SOC.

Figure 2 below shows a histogram of the number of reports per TOD second versus TOD relative to the TOD of the leap second. TOD 23:59:60 is shown on the histogram as 0 seconds. For an ideal PMU configured for a reporting rate of 60 frames per second, there will be 60 reports each Time of Day second (including the leap second, TOD 23:59:60). As shown in Section 3, the commercial PMUs' response to the leap second is different than for the ideal case. 


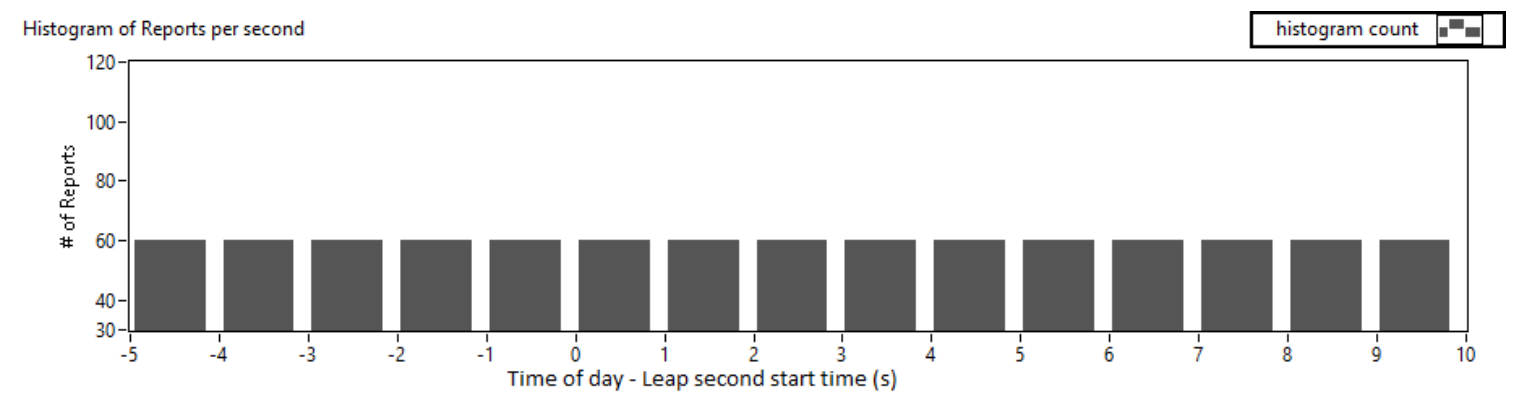

Figure 2: Ideal Histogram of Reports per SOC

\section{IRIG response to leap second}

The GPS receiver used in this investigation was configured to output IRIG-200, B000 format serial timecode with IEEE $1344^{\text {TM }}-1995$ compliant control bits. According to IEEE 1344 Annex F, the Leap Second Pending bit should transition from 0 to one no less than one second or greater than 59 seconds before the insertion of the leap second. IRIG-200 makes no mention whether the BCD second should progress to 60 or repeat 59 during the leap second insertion, nor does it specify if the SBS count should count one additional second of the day or repeat the last second of the day, IEEE 1344 states that "Leap seconds are always inserted at UTC midnight by altering the second time count only". Thus in UTC time, the time count goes from 23:59:59 to 23:59:60 to 00:00:00 to add the extra second." There is no specific guidance on whether the SBS count should add an extra second or repeat the last count.

The GPS receiver used in this investigation did not fully comply with IEEE-1344 in two ways:

1. The BCD second and SBS count repeated 23:59:59 and did not progress to 23:59:60 before going to 00:00:00.

2. The Leap Second Pending bit transitioned from 0 to 1 at 23:58:59, (one second early) and from 1 to 0 during the repeated 23:59:59, one second before the transition to 00:00:00 as specified.

\section{PMU responses to leap second}

8 PMUs were tested. 7 PMUs were tested at reporting rate of 60 frames per second (FPS). 1 PMU was tested at reporting rate of 30 FPS. PMU ID 1 uses an external GPS receiver made by the same manufacturer as the PMU. PMU IDs 2 through 4 have internal GPS receivers. PMU IDs 5 through 8 received IRIG B000 with IEEE 1344 extension [2] [1]. Deviation from the specified response are shown in red in this section.

\subsection{PMU ID 1 response to leap second}

PMU ID 1 uses an external GPS receiver of the same brand as the PMU and receives timing information via IRIG over coaxial cable and Pulse per Second via optical fiber [2]. PMU ID 1's IRIG input was not tested to determine whether or not the IRIG contained IEEE 1344 extension bits. PMU ID 1's response to the leap second is shown in Table 2.

Summary of PMU ID 1 Response: SOC 1435708799 never repeats (there is no TOD 23:59:60 represented). SOC 1435708816 repeats, so the SOC is unsynchronized with UTC for 17 seconds after the leap second occurs and becomes synchronized thereafter. PMU 1 did not set any time quality flag bits.

Table 2: PMU ID1 response to leap second

\begin{tabular}{|l|l|l|l|l|l|l|}
\hline SOC Time & FRACSEC & Time of Day & Direction & Occurred & Pending & Comment \\
\hline 1435708798 & .98333 & $23: 59: 58.9833$ & 0 & 0 & 0 & \\
\hline 1435708799 & .00000 & $23: 59: 59.0000$ & 0 & 0 & 0 & $\begin{array}{l}\text { Pending bit should be set no later than } \\
\text { here }\end{array}$ \\
\hline 1435708799 & .01667 & $23: 59: 59.0167$ & 0 & 0 & 0 & \\
\hline
\end{tabular}




\begin{tabular}{|c|c|c|c|c|c|c|}
\hline 1435708799 & .98333 & $23: 59: 59.9830$ & 0 & 0 & 0 & \\
\hline 1435708800 & .00000 & 00:00:00.0000 & 0 & 0 & 0 & $\begin{array}{l}\text { This is Leap Second. SOC did not } \\
\text { repeat; Occurred bit is not set }\end{array}$ \\
\hline 1435708800 & .01667 & 00:00:00.0167 & 0 & 0 & 0 & \\
\hline 1435708800 & 08333 & $00 \cdot 00 \cdot 009833$ & 0 & 0 & 0 & \\
\hline 1435708801 & 年 & $00: 00: 01.0000$ & 0 & 0 & 0 & SOC remains 1 second ahead of UTC \\
\hline 1435708801 & .01667 & 00:00:01.0167 & 0 & 0 & 0 & \\
\hline 1435708816 & 98333 & $00 \cdot 00 \cdot 169833$ & 0 & 0 & 0 & \\
\hline 1435708816 & .00000 & 00:00:16.0000 & 0 & 0 & 0 & $\begin{array}{l}\text { SOC repeats at } 17 \text { seconds after Leap } \\
\text { Second }\end{array}$ \\
\hline 1435708816 & .01667 & 00:00:16.0167 & 0 & 0 & 0 & SOC is now synchronized with UTC \\
\hline 1435795199 & .98333 & 23:59:56.9833 & 0 & 0 & 0 & \\
\hline 1435795200 & .00000 & 00:00:00.0000 & 0 & 0 & 0 & Occurred bit was never set \\
\hline 1435795200 & .01667 & 00:00:00.0000 & 0 & 0 & 0 & \\
\hline
\end{tabular}

Figure 3 shows a histogram of the number of reports per TOD second versus TOD relative to the leap second for PMU ID1. There were no reports during the leap second, TOD 23:59:60. The SOC repeated 17 seconds after the start of leap second so there are 120 reports during that SOC.

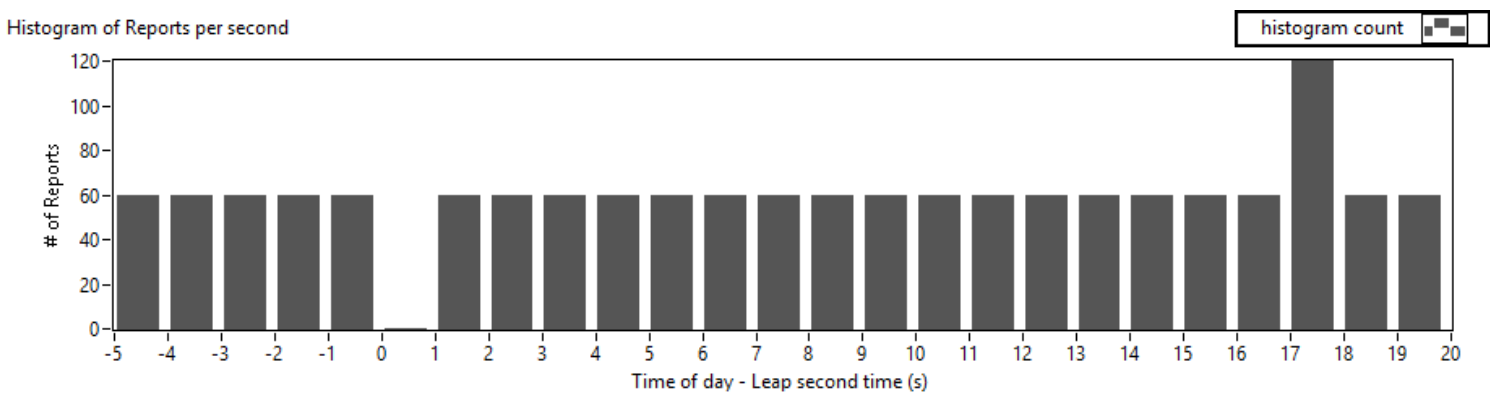

Figure 3: PMU ID1 Histogram of reports per SOC

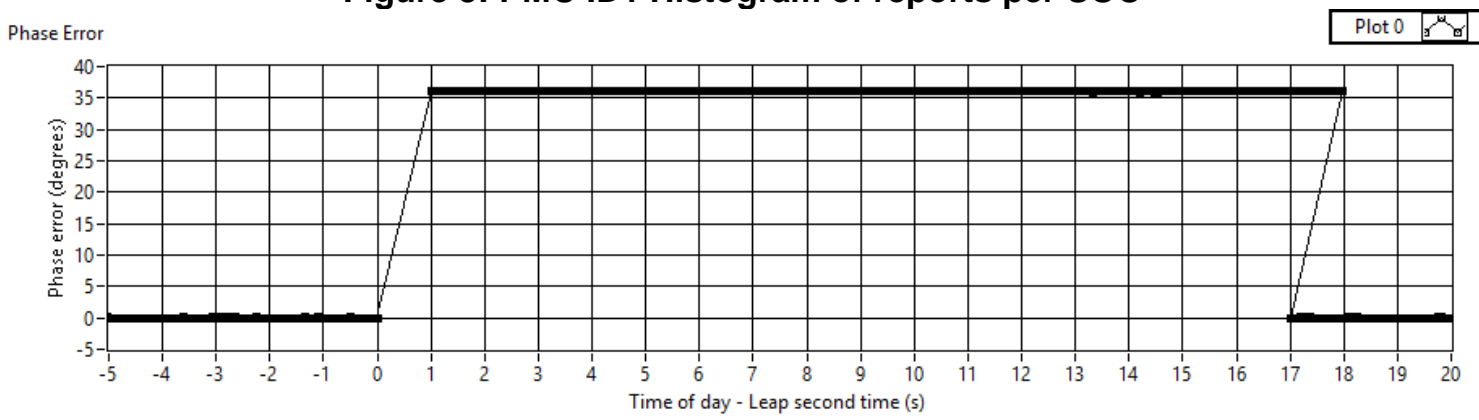

Figure 4: PMU ID 1 Phase Error at $59.9 \mathrm{~Hz}$ system frequency

Figure 4 shows the phase error in degrees for PMU ID 1. When each PMU report is aligned and compared with the actual input phase at the time of the PMU timestamp, the plotted phase errors result. The input signal was set to a steady state power system frequency of $59.9 \mathrm{~Hz}$. Since the synchrophasor rotates at 36 degrees per second, a onesecond error in reporting time will result in a 36 degree error in phase. There are no data between $0 \mathrm{~s}$ and $1 \mathrm{~s}$ because the PMU did not output any reports with a repeated SOC 1435708799 (TOD 23:59:60). There are two sets of data for the TOD from leap second (LS) +17 to +18 seconds. 


\subsection{PMU ID 2 response to leap second}

PMU ID 2 operates at maximum reporting rate of 30 FPS. PMU ID 2 uses an internal GPS receiver. PMU ID 2's response to the leap second is shown in Table 3.

Summary of PMU ID 2 Response: PMU did not repeat SOC 1435708799 and remained 1 second ahead of UTC for 47 seconds after leap second occurs, then returns to synchronization thereafter. No Time Quality bits were set.

Table 3: PMU ID 2 response to leap second

\begin{tabular}{|c|c|c|c|c|c|c|}
\hline SOC Time & FRACSEC & Time of Day & Direction & Occurred & Pending & Comment \\
\hline 1435708798 & .96667 & $23: 59: 58.9667$ & 0 & 0 & 0 & \\
\hline 1435708799 & .00000 & $23: 59: 59.0000$ & 0 & 0 & 0 & $\begin{array}{l}\text { Pending bit should be set no } \\
\text { later than here. }\end{array}$ \\
\hline 1435708799 & .00333 & $23: 59: 59.0333$ & 0 & 0 & 0 & \\
\hline $\begin{array}{l}14357087 \\
99\end{array}$ & .96667 & $23: 59: 59.9667$ & 0 & 0 & 0 & \\
\hline 1435708800 & .00000 & 00:00:00.0000 & 0 & 0 & 0 & $\begin{array}{l}\text { This is Leap Second. SOC } \\
\text { did not repeat; Occurred bit } \\
\text { is not set }\end{array}$ \\
\hline 1435708800 & .03333 & 00:00:00.0333 & 0 & 0 & 0 & \\
\hline 1435708800 & .96667 & 00:00:00.9667 & 0 & 0 & 0 & \\
\hline 1435708801 & .00000 & 00:00:01.0000 & 0 & 0 & 0 & $\begin{array}{l}\text { SOC remains } 1 \mathrm{~s} \text { ahead of } \\
\text { UTC }\end{array}$ \\
\hline 1435708801 & .03333 & 00:00:01.0333 & 0 & 0 & 0 & \\
\hline & & & & & & \\
\hline 1435708846 & .96667 & 00:00:46.9667 & 0 & 0 & 0 & \\
\hline 1435708846 & .00000 & 00:00:46.0000 & 0 & 0 & 0 & $\begin{array}{l}\text { SOC repeats } 47 \text { seconds } \\
\text { after } \mathrm{LS}\end{array}$ \\
\hline 1435708846 & .03333 & 00:00:46:0333 & 0 & 0 & 0 & $\begin{array}{l}\text { SOC is now synchronized } \\
\text { with UTC }\end{array}$ \\
\hline 1435795199 & .98333 & $23: 59: 56.9833$ & 0 & 0 & 0 & \\
\hline 1435795200 & .00000 & 00:00:00.0000 & 0 & 0 & 0 & Occurred bit was never set \\
\hline 1435795200 & .01667 & 00:00:00.0000 & 0 & 0 & 0 & \\
\hline
\end{tabular}

Figure 5 shows a histogram of the number of reports per TOD second versus TOD relative to the leap second for PMU 2. There were no reports for Time of Day 23:59:60 because the PMU did not repeat the LS SOC. The SOC repeated the SOC 47.0 seconds after the start of leap second, so there are 60 reports during that time. Note that PMU ID 2 was configured for reporting rate of 30 frames per second. 


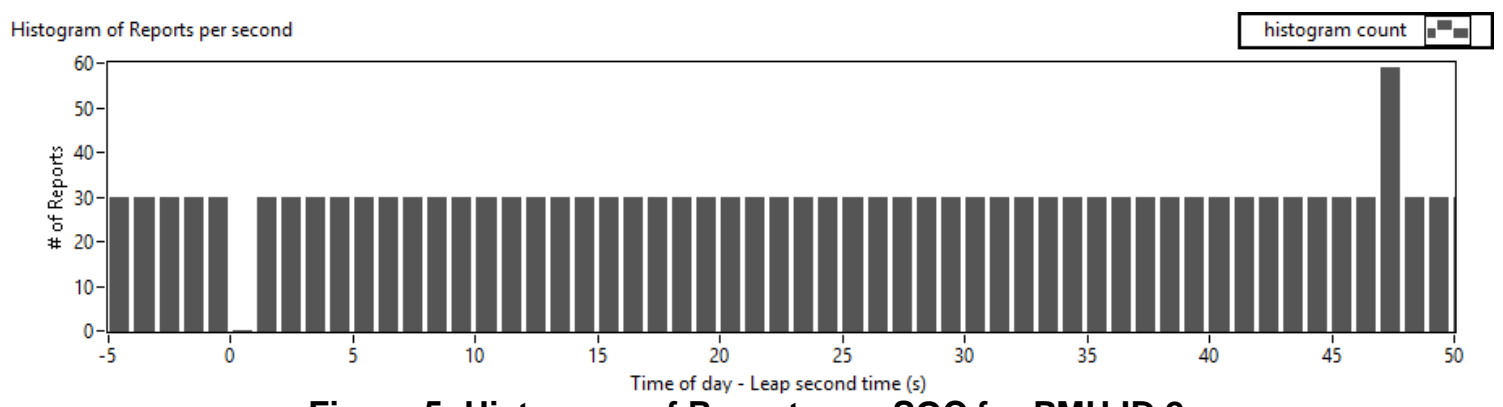

Figure 5: Histogram of Reports per SOC for PMU ID 2

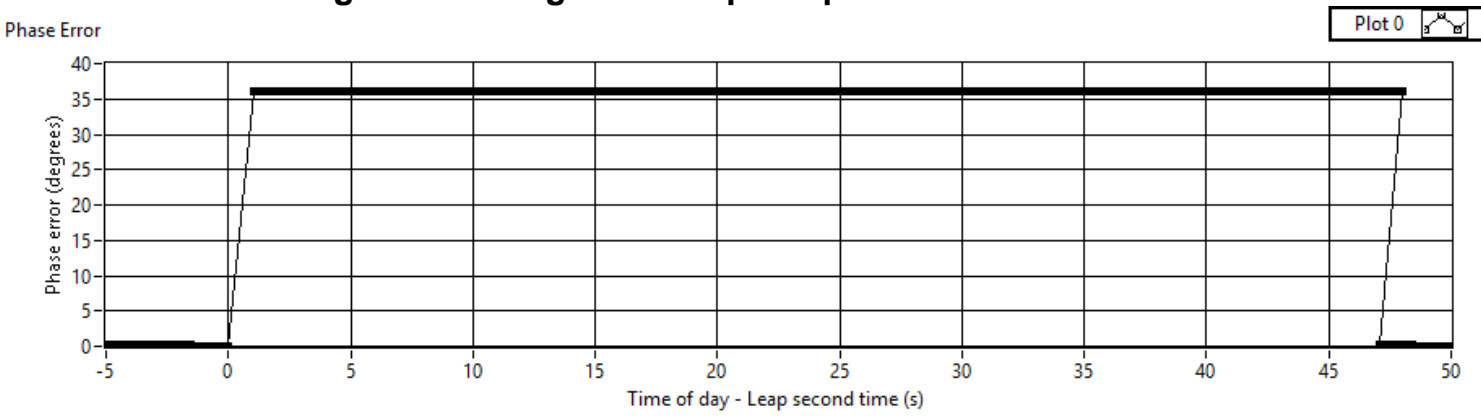

Figure 6: PMU ID 2 Phase Error

Figure 6 shows the phase error in degrees for PMU ID 2. When each PMU report is aligned and compared with the actual input phase at the time of the PMU timestamp the plotted phase errors result. The input signal was set to a steady state power system frequency of $59.9 \mathrm{~Hz}$. Since the synchrophasor rotates at 36 degrees per second, a onesecond error in reporting time will result in a 36 degree error in phase. There are no data between 0s (LS) and LS + 1s because the PMU did not output any reports with a repeated SOC 1435708799 (TOD 23:59:60). There are two sets of data for the time from LS +47 to $\mathrm{LS}+48$ seconds. 


\subsection{PMU ID 3 response to leap second}

PMU ID 3's response to the leap second is shown in Table 4. PMU ID 3 uses an internal GPS receiver.

Summary of PMU ID 3 Response: PMU did not repeat SOC 1435708799; the Pending and Occurred bits are set at incorrect times; SOC was one second ahead of UTC for 4 seconds, then portions of SOCs 1435708802 and 1435708802 are repeated; following the leap second, some SOCs had only 46 rather than 60 reports per second; the PMU continues to sporadically output 46 reports per second while primarily outputting 60 reports per second.

Table 4: PMU ID 3 response to leap second

\begin{tabular}{|c|c|c|c|c|c|c|}
\hline SOC Time & FRACSEC & Time of Day & Direction & Occurred & Pending & Comment \\
\hline 1435708739 & .06667 & $11: 58: 59.0667$ & 0 & 0 & 0 & \\
\hline 1435708739 & .08333 & $11: 58: 59.0833$ & 0 & 0 & 1 & Pending bit set $0.91667 \mathrm{~s}$ early. \\
\hline 1435708739 & .10000 & $11: 58: 59.1000$ & 0 & 0 & 1 & \\
\hline 1435708798 & .88333 & $11: 59: 58.8833$ & 0 & 0 & 1 & \\
\hline 1435708798 & .90000 & $11: 59: 58.9000$ & 0 & 1 & 0 & $\begin{array}{l}\text { Pending bit cleared and Occurred } \\
\text { bit set } 1.1 \mathrm{~s} \text { early }\end{array}$ \\
\hline 1435708798 & .91667 & 11:59:58.9166 & 0 & 1 & 0 & \\
\hline 1435708799 & .98333 & $11: 59: 59.9833$ & 0 & 1 & 0 & \\
\hline 1435708800 & .00000 & 00:00:00.0000 & 0 & 1 & 0 & $\begin{array}{l}\text { This is Leap Second. SOC did not } \\
\text { repeat; }\end{array}$ \\
\hline 1435708800 & .01667 & 00:00:00.0000 & 0 & 1 & 0 & \\
\hline 1435708800 & .98333 & 00:00:00.9833 & 0 & 1 & 0 & $\begin{array}{l}\text { There were only } 46 \text { reports during } \\
\text { TOD 00:00:00. }\end{array}$ \\
\hline 1435708801 & .00000 & 00:00:01.000 & 0 & 1 & 0 & SOC remains $1 \mathrm{~s}$ ahead of UTC \\
\hline 1435708801 & .01666 & 00:00:01.0167 & & & & $\begin{array}{l}\text { There were only } 46 \text { reports during } \\
\text { TOD 00:00:01 }\end{array}$ \\
\hline 1435708803 & .88333 & 00:00:03.8833 & 0 & 1 & 0 & \\
\hline 1435708802 & .90000 & $00: 00: 02.9000$ & 0 & 1 & 0 & SOC skips back $0.9833 \mathrm{~s}$ \\
\hline 1435708802 & 91667 & 00:00:02.9167 & 0 & 1 & 0 & $\begin{array}{l}\text { SOC would be synchronized with } \\
\text { UTC, except for missing reports }\end{array}$ \\
\hline 1435795199 & .98333 & $23: 59: 56.9833$ & 0 & 1 & 0 & \\
\hline 1435795200 & .00000 & 00:00:00.0000 & 0 & 1 & 0 & Occurred bit did not reset \\
\hline 1435795200 & .01667 & 00:00:00.0000 & 0 & 1 & 0 & \\
\hline
\end{tabular}

Figure 7 shows a histogram of the number of reports per TOD second versus TOD relative to the leap second for PMU ID 3. There were no reports during TOD 23:59:60 because the PMU did not repeat the LS SOC. Beginning one second after the leap second, the PMU only transmitted 46 reports for the following 3 seconds. However, following 00:00:03.8833, the PMU SOC skipped back to 00:00:02.9000; thus for 00:00:02 there were 50 reports but 4 of them occurred 1 second later. The SOC 00:00:03 had 88 reports (2 seconds worth of 46 reports per second minus the four reports from 00:00:02), then 00:00:04 had 46 reports. After that there were 60 reports per SOC for a while but the PMU began to sporadically output 46 reports per SOC for the following 8 days. After 8 days, the PMU was power cycled but continues to sporadically output 46 reports per SOC with 14 reports missing. 


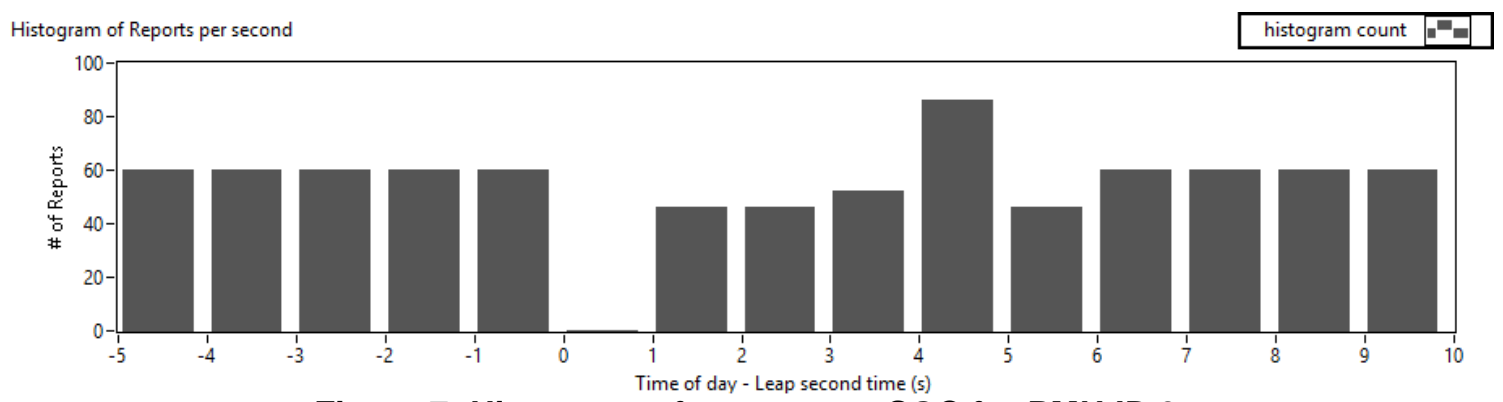

Figure 7: Histogram of reports per SOC for PMU ID 3

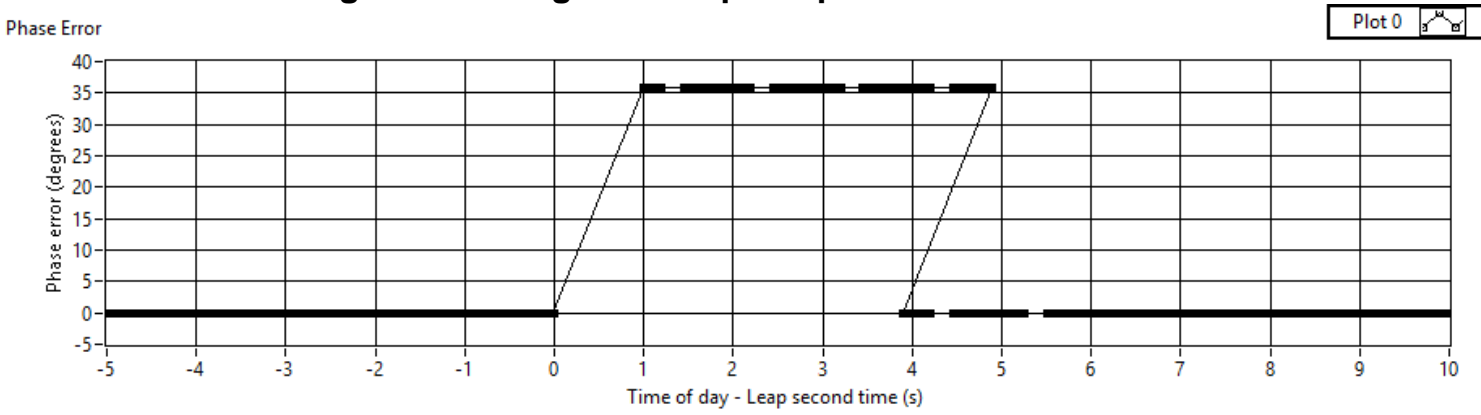

Figure 8: PMU ID 3 Phase Error

Figure 8 shows the phase error in degrees for PMU ID 3. When each PMU report is aligned and compared with the actual input phase at the TOD of the PMU timestamp the plotted phase errors result. The input signal was set to a steady state power system frequency of $59.9 \mathrm{~Hz}$. Since the synchrophasor rotates at 36 degrees per second, a onesecond error in reporting time will result in a 36 degree error will result in phase. Note that there are no data between 0 s and 1s because the PMU did not repeat the LS SOC. There are two sets of data for the time from LS + 2.900 to LS +4.900 seconds. Also, note also that there are gaps in the data from those seconds where only 46 reports were output.

Figure 9 shows how PMU 3 sporadically outputs 46 reports during some SOCs. The PMU continues to do this even though it has been shut down and re-started.

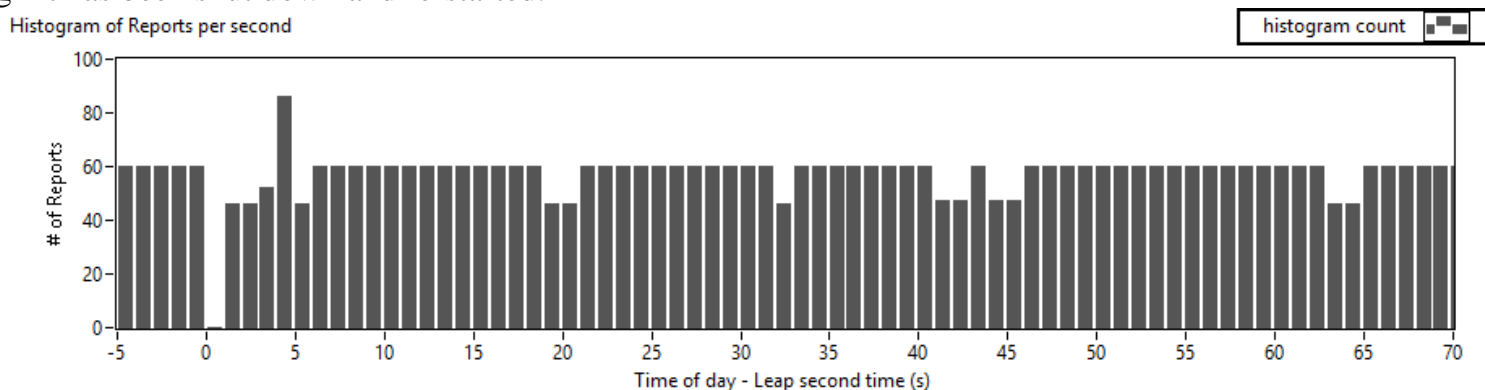

Figure 9: Histogram of reports per SOC for PMU ID 3 showing sporadic lost reports 


\subsection{PMU ID 4 response to leap second}

PMU ID 4's response to the leap second is shown in Table 5. PMU 4 uses an internal GPS receiver.

Summary of PMU ID 4 Response: SOC 1435708799 did not repeat immediately after TOD 23:59:59. After 8 reports with SOC 1435708800 (TOD 00:00:00) SOC changed back to 1435708799 (TOD 23:59:60); so for 0.15 seconds, the SOC was one second ahead of UTC. There were 52 reports during TOD 23:59:60. The leap second Pending flag was reset and the Occurred flag was set at 1.333 seconds after the leap second.

Table 5: PMU ID 4 response to leap second

\begin{tabular}{|c|c|c|c|c|c|c|}
\hline SOC Time & FRACSEC & Time of Day & Direction & Occurred & Pending & Comment \\
\hline 1435708741 & .10000 & $23: 59: 01.1000$ & 0 & 0 & 0 & \\
\hline 1435708741 & .11667 & 23:59:01.1167 & 0 & 0 & 1 & $\begin{array}{l}\text { Pending bit was set within limits } \\
\text { of not more than } 60 \text { s nor less than } \\
1 \text { second before LS. }\end{array}$ \\
\hline 1435708741 & .13333 & 23:59:01.1333 & 0 & 0 & 1 & \\
\hline 1435708799 & .98333 & $23: 59: 59.9833$ & 0 & 0 & 1 & \\
\hline 1435708800 & .00000 & 00:00:00.0000 & 0 & 0 & 1 & $\begin{array}{l}\text { This is Leap Second. SOC did not } \\
\text { repeat; Occurred bit is not set }\end{array}$ \\
\hline 1435708800 & .01667 & 00:00:00.0167 & 0 & 0 & 1 & \\
\hline 1435708800 & .11667 & 00:00:00.1167 & 0 & 0 & 1 & \\
\hline 1435708799 & .13333 & $23: 59: 60.1333$ & 0 & 0 & 1 & $\begin{array}{l}\text { Rolled BACK to 23:59:60 but LS } \\
\text { Pending bit is still set }\end{array}$ \\
\hline 1435708799 & .16667 & 23:59:60.1667 & 0 & 0 & 1 & \\
\hline 1435708799 & .98333 & $23: 59: 60.9833$ & 0 & 0 & 1 & \\
\hline 1435708800 & .00000 & 00:00:00.0000 & 0 & 0 & 1 & $\begin{array}{l}\text { Rolled over again to 00:00:00 but } \\
\text { LS Pending bit is still set }\end{array}$ \\
\hline 1435708800 & .01167 & 00:00:00.0117 & 0 & 0 & 1 & \\
\hline 1435708800 & .11667 & 00:00:00.1167 & 0 & 0 & 1 & \\
\hline 1435708800 & .13333 & 00:00:00.1333 & 0 & 1 & 0 & $\begin{array}{l}\text { LS Pending bit is reset; Occurred } \\
\text { bit is set; both are late }\end{array}$ \\
\hline 1435708800 & .15000 & 00:00:00.1500 & 0 & 1 & 0 & \\
\hline 1435795200 & .11667 & 00:00:00.1167 & 0 & 1 & 0 & \\
\hline 1435795200 & .15000 & 00:00:00.1500 & 0 & 0 & 0 & $\begin{array}{l}\text { Occurred bit was reset } 0.15 \\
\text { seconds late }\end{array}$ \\
\hline 1435795200 & .01667 & 00:00:00.0000 & 0 & 0 & 0 & \\
\hline
\end{tabular}

Figure 10 shows a histogram of the number of reports per TOD second versus TOD relative to the leap second for PMU ID 4. At the time of the leap second, instead of reporting TOD 23:59:60, the PMU rolled over to 00:00:00 for 8 reports then skipped back to 23:59:60.1333. There were 68 reports for TOD 00:00:00 and 52 reports for TOD 23:59:60 (8 of which occurred at the incorrect time). 


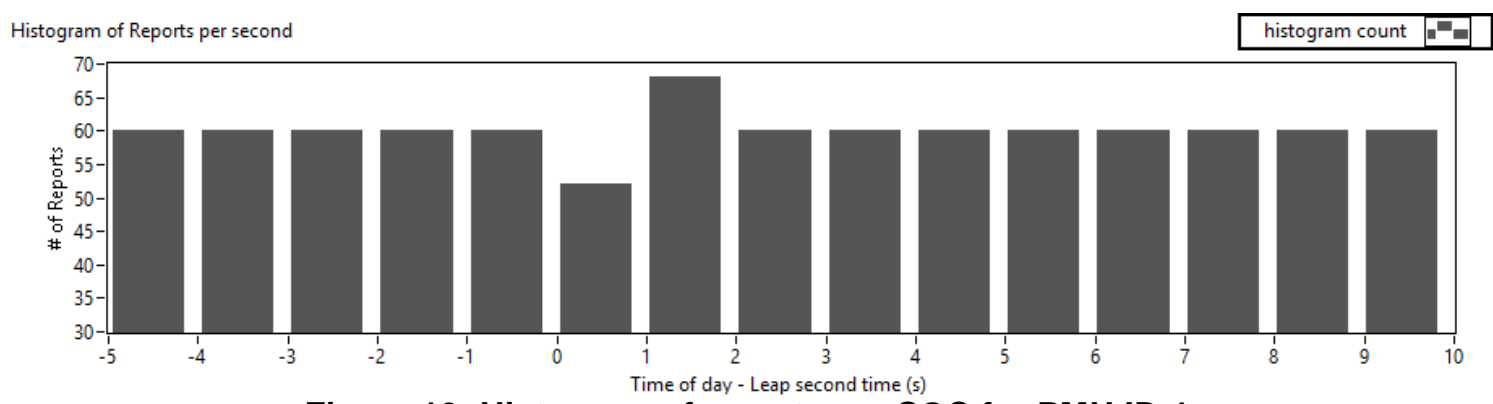

Figure 10: Histogram of reports per SOC for PMU ID 4

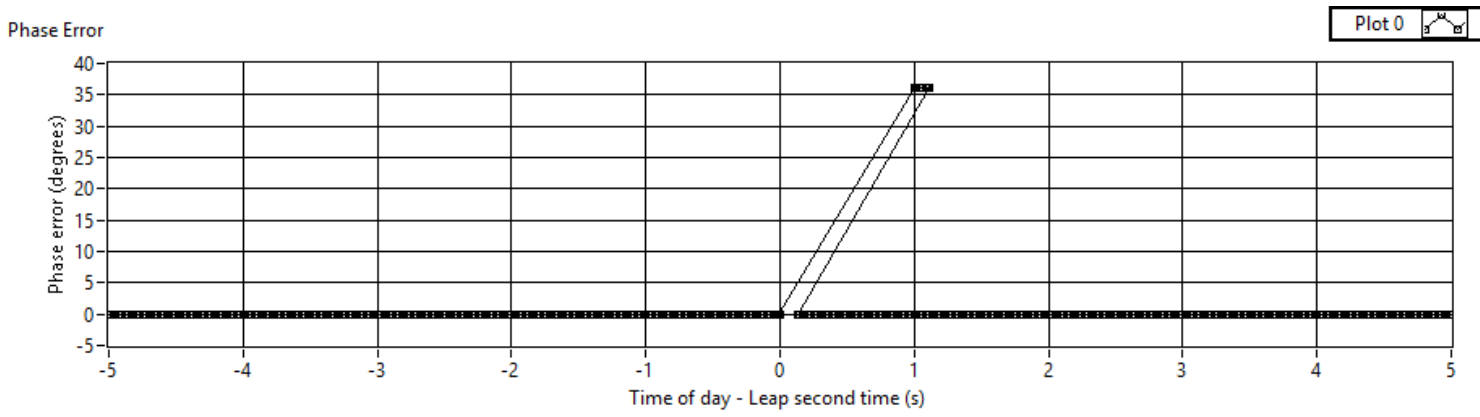

Figure 11: PMU ID 4 Phase Error

Figure 11 shows the phase error in degrees for PMU ID 4. When each PMU report is aligned and compared with the actual input phase at the time of the PMU timestamp the plotted phase errors result. The input signal was set to a steady state power system frequency of $59.9 \mathrm{~Hz}$. Since the synchrophasor rotates at 36 degrees per second a onesecond error in reporting time will result in a 36 degree error in phase. Note that the there are no data between 0.0000 $\mathrm{s}$ and $0.1667 \mathrm{~s}$ because the PMU rolled over to 00:00:00 (1 second after Leap Second). After 7 reporting periods, the SOC skipped back to UTC time at 23:59:60.1667. There are two sets of data for the relative LS + 1.000 s to LS + $1.1667 \mathrm{~s}$ 


\subsection{PMU ID 5 response to leap second}

PMU ID 5 timing signal input is from IRIG B000 with IEEE 1344 extension. Note the deviation from IEEE 1344 format in section 3. PMU ID 5's response to the leap second is shown in Table 6.

Summary of PMU ID 5 Response: LS bits did not get set. SOC 1435708799 did not repeat following TOD 23:59:59 and remained one second ahead of UTC for 1.933 seconds after LS but gets synchronized thereafter.

Table 6: PMU ID 5 response to leap second

\begin{tabular}{|c|c|c|c|c|c|c|}
\hline SOC Time & FRACSEC & Time of Day & Direction & Occurred & Pending & Comment \\
\hline 1435708798 & 98333 & $23: 59: 58.9833$ & 0 & 0 & 0 & \\
\hline 1435708799 & .00000 & $23: 59: 59.0000$ & 0 & 0 & 0 & $\begin{array}{l}\text { Pending bit should be set no later than } \\
\text { here }\end{array}$ \\
\hline 1435708799 & .01667 & 23:59:59.0167 & 0 & 0 & 0 & \\
\hline 1435708799 & .98333 & $23: 59: 59.9830$ & 0 & 0 & 0 & \\
\hline 1435708800 & .00000 & 00:00:00.0000 & 0 & 0 & 0 & $\begin{array}{l}\text { This is Leap Second. SOC did not } \\
\text { repeat; Occurred bit is not set }\end{array}$ \\
\hline 1435708800 & .01667 & 00:00:00.0167 & 0 & 0 & 0 & \\
\hline & & & & & & \\
\hline 1435708800 & .98333 & 00:00:00.9833 & 0 & 0 & 0 & \\
\hline 1435708801 & .00000 & 00:00:00.0000 & 0 & 0 & 0 & SOC remains 1 second ahead of UTC \\
\hline 1435708801 & .01667 & 00:00:00.0167 & 0 & 0 & 0 & \\
\hline & & & & & & \\
\hline $\begin{array}{l}1435 / 08801 \\
1435708800\end{array}$ & $\begin{array}{l}.9166 / \\
.93333\end{array}$ & $\begin{array}{l}\text { 00:00:01.9167 } \\
00: 00: 00.9333\end{array}$ & $\begin{array}{l}0 \\
0\end{array}$ & $\begin{array}{l}0 \\
0\end{array}$ & $\begin{array}{l}0 \\
0\end{array}$ & SOC goes back by 1 second at 1.9333 \\
\hline & & & & & & seconds after LS \\
\hline 1435708800 & .95000 & 00:00:00.9500 & 0 & 0 & 0 & \\
\hline 1435795199 & 08333 & $23.59 \cdot$ & 0 & & & \\
\hline 1435795200 & .00000 & $00 \cdot 00 \cdot 00.0000$ & 0 & 0 & 0 & red bit was never set \\
\hline 1435795200 & .01667 & 00:00:00.0000 & 0 & 0 & 0 & \\
\hline
\end{tabular}

Figure 12 shows a histogram of the number of reports per TOD second versus TOD relative to the leap second for PMU ID 5. There are no reports for TOD 23:59:60 because the PMU did not repeat the LS SOC. The PMU rolled back the SOC by 1 second at 1.9333 seconds after LS so there are 64 reports for TOD 00:00:00 and 116 reports for TOD 00:00:01.

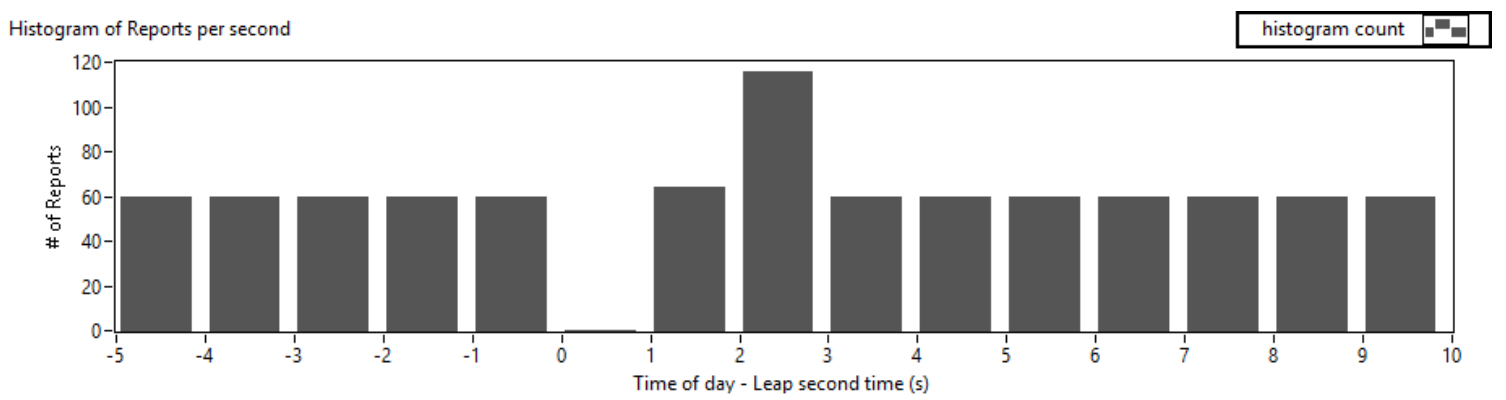

Figure 12: Histogram of reports per SOC for PMU 5

Due to an error made by the operator of the PMU, PMU ID 5's configuration data did not contain data scale factor information, so there are no phase error data available for PMU ID 5. 


\subsection{PMU ID 6 response to leap second}

PMU ID 6 timing signal input is from IRIG B000 with IEEE 1344 extension. Note the deviation from IEEE 1344 in section 3. PMU ID 6's response to the leap second is shown in Table 7.

Summary of PMU ID 6 response: LS bits do not get set. SOC did not repeat after TOD 23:59:59 and remained 1 second ahead of UTC for 4 seconds after LS but gets synchronized thereafter.

Table 7: PMU ID 6 response to leap second

\begin{tabular}{|c|c|c|c|c|c|c|}
\hline SOC Time & FRACSEC & Time of Day & Direction & Occurred & Pending & Comment \\
\hline 1435708798 & .98333 & $23: 59: 58.9833$ & 0 & 0 & 0 & \\
\hline 1435708799 & .00000 & 23:59:59.0000 & 0 & 0 & 0 & $\begin{array}{l}\text { Pending bit should be set no later than } \\
\text { here }\end{array}$ \\
\hline 1435708799 & .01667 & 23:59:59.0167 & 0 & 0 & 0 & \\
\hline 1435708799 & & 0250500020 & & & & \\
\hline 1435708800 & 年00000 & $\frac{25.59 .59 .9850}{00: 00: 00.0000}$ & 0 & 0 & 0 & $\begin{array}{l}\text { This is Leap Second. SOC did not } \\
\text { repeat; Occurred bit was not set }\end{array}$ \\
\hline 1435708800 & .01667 & 00:00:00.0167 & 0 & 0 & 0 & \\
\hline & ג000? & $200 \cdot 00.000823$ & & & & \\
\hline 1435708801 & $\begin{array}{l}.00555 \\
.00000\end{array}$ & $00: 00: 00.0000$ & 0 & 0 & 0 & SOC remains 1 second ahead of UTC \\
\hline 1435708801 & .01667 & 00:00:00.0167 & 0 & 0 & 0 & \\
\hline 1435708803 & 98333 & $00 \cdot 00 \cdot 039833$ & 0 & 0 & 0 & \\
\hline 1435708803 & .00000 & 00:00:03.0000 & 0 & 0 & 0 & SOC repeats 4 seconds after LS \\
\hline 1435708803 & .01667 & 00:00:03.0167 & 0 & 0 & 0 & \\
\hline 1435795199 & 98333 & $23 \cdot 59 \cdot 569833$ & 0 & 0 & 0 & \\
\hline 1435795200 & .00000 & 00:00:00.0000 & 0 & 0 & 0 & Occurred bit was never set \\
\hline 1435795200 & .01667 & 00:00:00.0000 & 0 & 0 & 0 & \\
\hline
\end{tabular}

Figure 13 shows a histogram of the number of reports per TOD second versus TOD relative to the leap second for PMU ID 6. The SOC repeated 4 seconds after the leap second so there are no reports for TOD 23:59:60 and 120 reports for TOD 00:00:03.

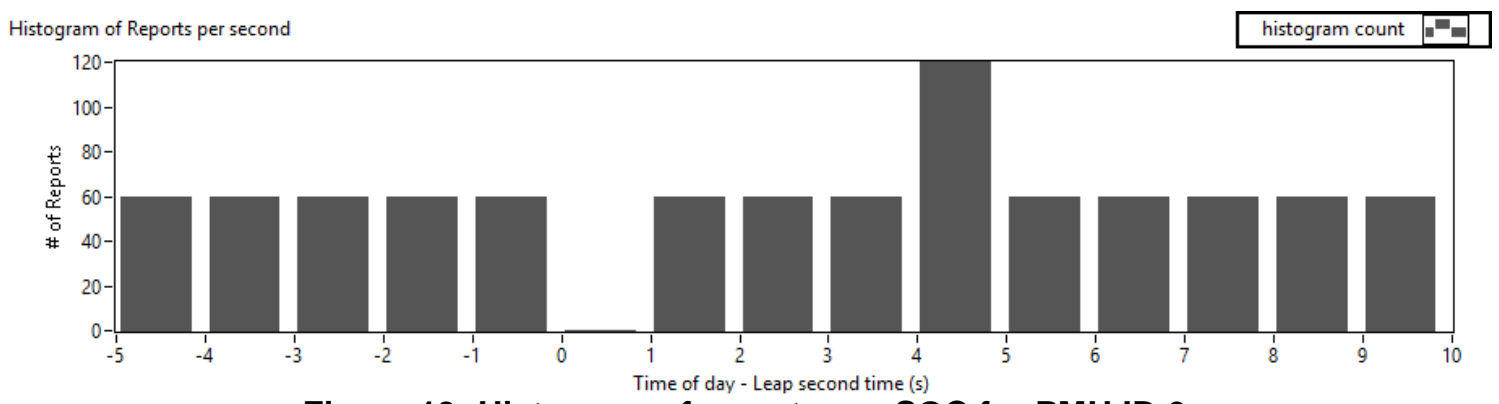

Figure 13: Histogram of reports per SOC for PMU ID 6 


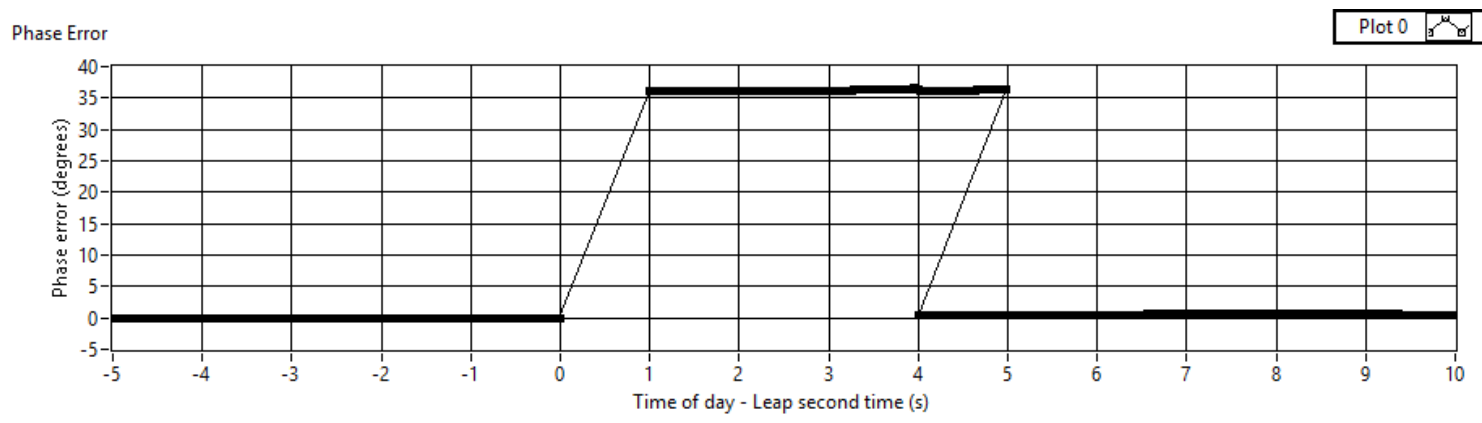

Figure 14: PMU ID 6 Phase Error

Figure 14 shows the phase error in degrees for PMU ID 6. When each PMU report is aligned and compared with the actual input phase at the time of the PMU timestamp the plotted phase errors result. The input signal was set to a steady state power system frequency of $59.9 \mathrm{~Hz}$. Since the synchrophasor rotates at 36 degrees per second, a onesecond error in reporting time will result in a 36 degree error in phase. Note that there are no data from LS to LS + 1 $s$ because the PMU did not repeat the LS SOC. There are two sets of data for the LS + 4 to LS +5 seconds. 


\subsection{PMU ID 7 response to leap second}

PMU ID 7 timing signal input is from IRIG B000 with IEEE 1344 extension. Note the deviation from IEEE 1344 in section 3. PMU ID 7 response to leap second is shown in

Summary of PMU ID 7 Response: LS flags do not get set. SOC did not repeat after TOD 23:59:59 and remained 1 second ahead of UTC for 2 seconds after LS but gets synchronized thereafter.

Table 8: PMU ID 7 response to leap second

\begin{tabular}{|c|c|c|c|c|c|c|}
\hline SOC Time & FRACSEC & Time of Day & Direction & Occurred & Pending & Comment \\
\hline 1435708798 & .98333 & 23:59:58.9833 & 0 & 0 & 0 & \\
\hline 1435708799 & .00000 & 23:59:59.0000 & 0 & 0 & 0 & $\begin{array}{l}\text { Pending bit should be set no later than } \\
\text { here }\end{array}$ \\
\hline 1435708799 & .01667 & 23:59:59.0167 & 0 & 0 & 0 & \\
\hline 1435708799 & .98333 & 23:59:59.9830 & 0 & 0 & 0 & \\
\hline 1435708800 & .00000 & 00:00:00.0000 & 0 & 0 & 0 & $\begin{array}{l}\text { This is Leap Second. SOC did not } \\
\text { repeat, Occurred bit is not set }\end{array}$ \\
\hline 1435708800 & .01667 & 00:00:00.0167 & 0 & 0 & 0 & \\
\hline & & & & & & \\
\hline 1435708800 & .98333 & 00:00:00.9833 & 0 & 0 & 0 & \\
\hline 1435708801 & .00000 & 00:00:00.0000 & 0 & 0 & 0 & SOC remains 1 second ahead of UTC \\
\hline 1435708801 & .01667 & 00:00:00.0167 & 0 & 0 & 0 & \\
\hline & & & & & & \\
\hline 1435708801 & 98333 & 00:00:03.9833 & 0 & 0 & 0 & \\
\hline 1435708801 & .00000 & 00:00:03.0000 & 0 & 0 & 0 & SOC repeats 2 seconds after $\mathrm{LS}$ \\
\hline 1435708801 & .01667 & 00:00:03.0167 & 0 & 0 & 0 & \\
\hline 1435795199 & .98333 & 23:59:56.9833 & 0 & 0 & 0 & \\
\hline 1435795200 & .00000 & 00:00:00.0000 & 0 & 0 & 0 & Occurred bit was never set \\
\hline 1435795200 & 01667 & 00:00:00.0000 & 0 & 0 & 0 & \\
\hline
\end{tabular}

Figure 15 shows a histogram of the number of reports per TOD second versus TOD relative to the leap second for PMU ID 7. At 2 seconds after the LS, SOC repeats so there are no reports for TOD 23:59:60 and 120 reports for TOD 00:00:01

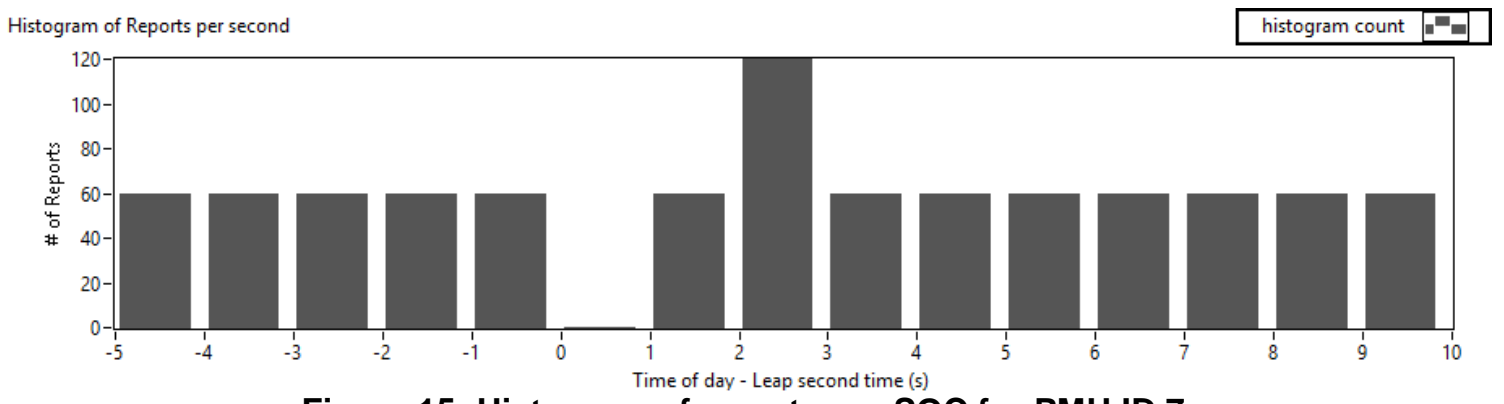

Figure 15: Histogram of reports per SOC for PMU ID 7 


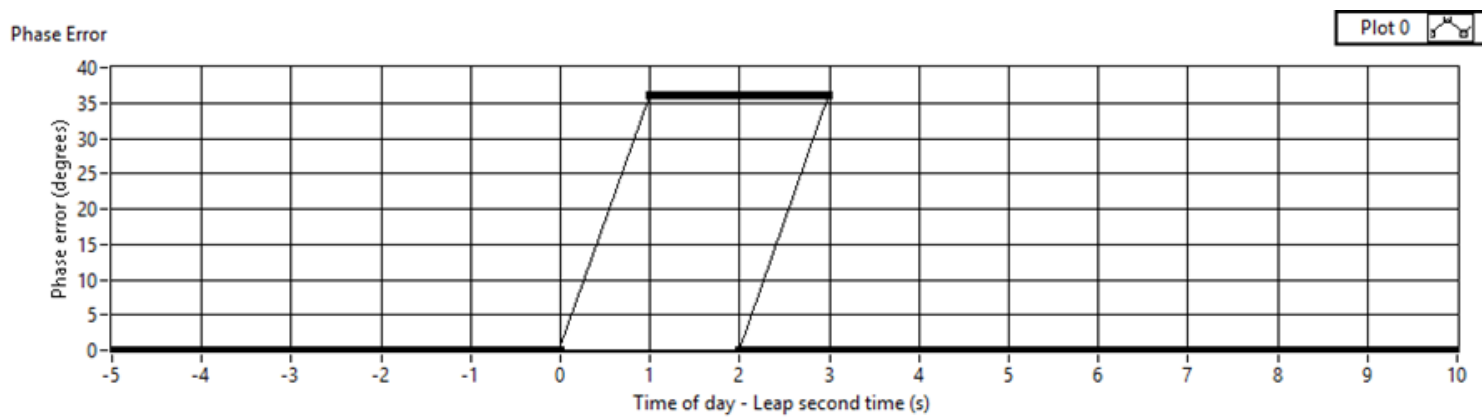

Figure 16: PMU ID 7 phase error

Figure 16 shows the phase error in degrees for PMU ID 7. When each PMU report is aligned and compared with the actual input phase at the time of the PMU timestamp the plotted phase errors result. The input signal was set to a steady state power system frequency of $59.9 \mathrm{~Hz}$. Since the synchrophasor rotates at 36 degrees per second, a onesecond error in reporting time will result in a 36 degree error in phase. Note that there are no data from LS to LS + 1 $\mathrm{s}$ because the PMU did not repeat the LS SOC. There are two sets of data for the LS $+2 \mathrm{~s}$ to LS $+3 \mathrm{~s}$. 


\subsection{PMU ID 8 response to leap second}

PMU ID 8 timing signal input is from IRIG B000 with IEEE 1344 extension. Note the deviation from IEEE 1344 in section 3. PMU ID 8 response to leap second is shown in Table 9.

Summary of PMU ID 8 Response: SOC 1435708740 (TOD 23:59:00) was repeated (this should not happen and may be related to the 1s early setting of the IRIG LSP). SOC 1435708742 follows the repeated SOC 1435708740 meaning that one minute before the leap second, the SOC was one second behind UTC for a period of one second. The LS SOC is not repeated, so for one second SOC is 1 second behind UTC. Then following SOC 1435708800 (TOD 00:00:00), the LS SOC repeats one second late (TOD 23:59:60), so for the next second, SOC is one second ahead of UTC. SOC 1435708801 (TOD 00:00:01) follows TOD 23:59:60 so the SOC becomes aligned with UTC thereafter.

Table 9: PMU ID 8 response to leap second

\begin{tabular}{|c|c|c|c|c|c|c|}
\hline SOC Time & FRACSEC & Time of Day & Direction & Occurred & Pending & Comment \\
\hline 1435708739 & .98333 & $23: 58: 59.9833$ & 0 & 0 & 0 & \\
\hline 1435708740 & .00000 & 23:59:00.0000 & 0 & 0 & 1 & $\begin{array}{l}\text { Pending bit was set within limits of not } \\
\text { more than } 60 \text { s nor less than } 1 \text { second } \\
\text { before from LS. }\end{array}$ \\
\hline 1435708740 & .13333 & 23:59:00.1333 & 0 & 0 & 1 & \\
\hline 1435708740 & .98333 & 23:59:00.9833 & 0 & 0 & 1 & \\
\hline 1435708740 & .00000 & 23:59:00.0000 & 0 & 1 & 0 & $\begin{array}{l}\text { 23:59:00 is repeated at this second at } 59 \\
\text { seconds before the actual LS. Pending bit } \\
\text { is not set; Occurred bit is set. This may be } \\
\text { a result of the IRIG LSP bit having been } \\
\text { set } 1 \text { second early. }\end{array}$ \\
\hline 1435708740 & .01667 & 23:59:00.0167 & 0 & 1 & 0 & \\
\hline 1435708740 & .98333 & 23:59:00.9833 & 0 & 1 & 0 & \\
\hline 1435708742 & .00000 & 23:59:02.0000 & 0 & 1 & 1 & $\begin{array}{l}\text { SOC and TOD advance by } 1 \text { second. LS } \\
\text { Pending and Occurred bits should are both } \\
\text { set at the same time (this should never } \\
\text { happen - see note 1) }\end{array}$ \\
\hline 1435708742 & .01667 & 23:59:02.0167 & 0 & 1 & 1 & \\
\hline 1435708799 & .98333 & 23:59:59.9833 & 0 & 1 & 1 & \\
\hline 1435708800 & .00000 & 00:00:00.0000 & 0 & 1 & 1 & $\begin{array}{l}\text { This is Leap Second. SOC did not repeat. } \\
\text { Pending and Occurred bits are still both set }\end{array}$ \\
\hline 1435708800 & .01667 & 00:00:00.0000 & & 1 & 1 & \\
\hline 1435708800 & .98333 & 00:00:00.9833 & & 1 & 1 & \\
\hline 1435708799 & .00000 & 23:59:60.0000 & & 1 & 0 & $\begin{array}{l}\text { SOC goes back by } 2 \text { seconds. Pending bit } \\
\text { is reset. }\end{array}$ \\
\hline 1435708799 & .01666 & 23:59:60.0000 & & 1 & 0 & \\
\hline 1435708799 & .98333 & 23:59:60.9833 & & 1 & 0 & \\
\hline 1435708801 & .00000 & 00:00:01.0000 & & 1 & 0 & $\begin{array}{l}\text { SOC skips ahead by } 1 \text { second. It is aligned } \\
\text { here with post-LS UTC. }\end{array}$ \\
\hline 1435708801 & .01666 & 00:00:01.01667 & & 1 & 0 & \\
\hline 1435795198 & .98333 & $23: 59: 56.9833$ & 0 & 1 & 0 & \\
\hline 1435795199 & .00000 & 00:00:00.0000 & 0 & 0 & 0 & Occurred bit was reset 1 second early \\
\hline 1435795199 & .01667 & 00:00:00.0000 & 0 & 0 & 0 & \\
\hline
\end{tabular}


Figure 17 shows a histogram of the number of reports per TOD second versus TOD relative to the leap second for PMU ID 8. PMU ID 8 repeated TOD 23:59:00 at 59 seconds before the leap second then skipped forward from TOD 23:59:00.9833 to TOD 23:59:02.0000. This may be a result of the IRIG LSP having been set 1 second early. There are 120 reports for the second beginning one minute before leap second and none during the following second. Furthermore, PMU ID 8 did not skip back to TOD 23:59:60 at the appropriate time but rather skipped back by 2 seconds at one second after the leap second. At the end of the TOD 23:59:60 reports, the PMU then skipped ahead by one second to TOD 00:00:01.

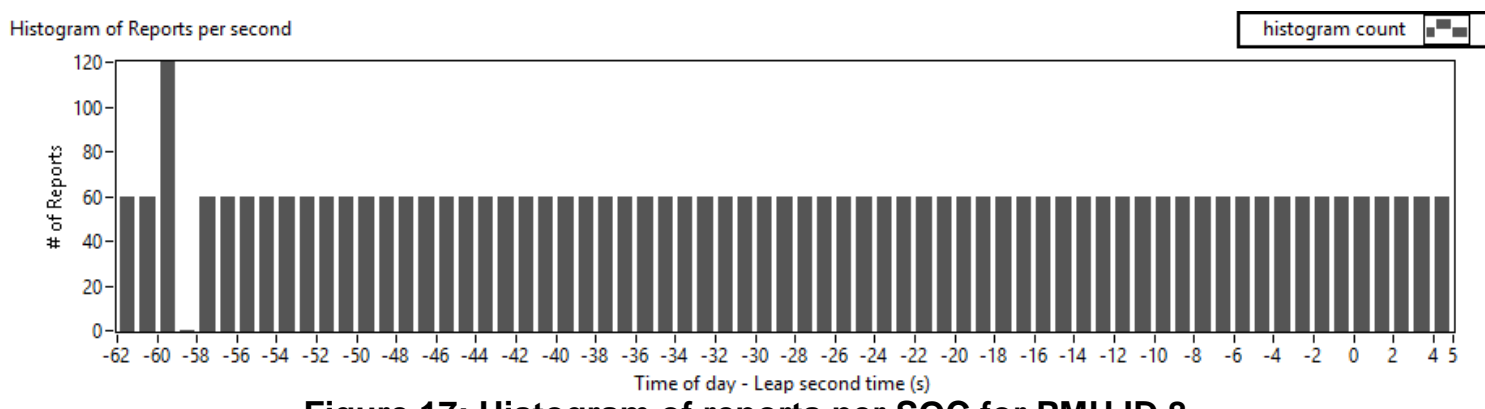

Figure 17: Histogram of reports per SOC for PMU ID 8

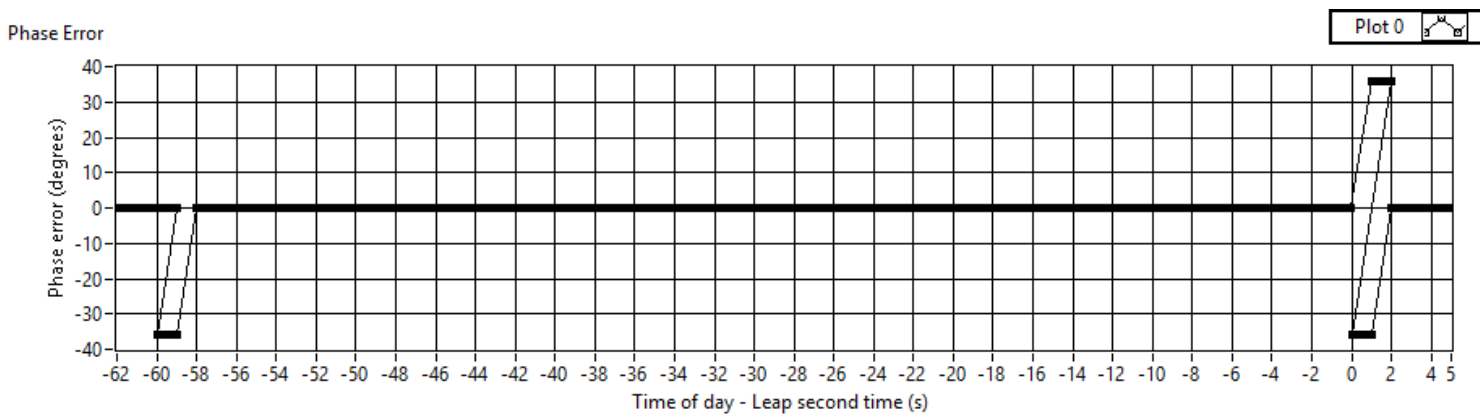

Figure 18: PMU ID 8 Phase Error

Figure 18 shows the phase error in degrees for PMU ID 8. When each PMU report is aligned and compared with the actual input phase at the time of the PMU timestamp the plotted phase errors result. The input signal was set to a steady state power system frequency of $59.9 \mathrm{~Hz}$. Since the synchrophasor rotates at 36 degrees per second, a onesecond error in reporting time will result in a 36 degree error in phase. The phase error plot shows the effect of skipping back by one second at relative LS - 59 seconds, then skipping ahead one second later. During the leap second, the histogram shows that there were 60 reports per second, but the phase error plot shows that for 2 seconds after LS the timestamps reported were incorrect. The reports from the time of leap second to 1 second after were actually taken 1 second late, thus there was a -36 degree error, then the SOC skipped ahead by 2 seconds causing one second of +36 degree error before returning back to synchronization with UTC. 


\section{Conclusion}

The leap second testing of 8 PMUs at NIST shows that care should be taken when analyzing PMU data around the recent leap second. GPS receivers, IRIG timing signal sources, and PMUs should be tested and corrections made before the next leap second occurs. The results of this investigation also highlights the need for conformance testing of PMU response to leap second events. None of the PMUs remained synchronized with UTC during the leap second and all of them displayed that there would be missing data and errors in the synchrophasor data due to incorrect Second of Century in the report timestamps. Nonconformance in the IRIG timing input to four of the eight PMUs may or may not have contributed to the observed individual behaviors.

Most of the PMUs did not set the Time Quality Flags at all, and those that did had incorrect bit settings for the periods that they were set. Of particular note is that not only did the GPS receiver generating IRIG set its IEEE 1344 Leap Second Pending bit 1 second too early, but PMU 3 also set its leap second pending bit $0.91667 \mathrm{~s}$ ( $1 \mathrm{~s}-1$ PMU report) early. PMU 4, also with an internal GPS receiver, set its leap second bit within the IEEE 1344 requirement of no less than $1 \mathrm{~s}$ nor more than $59 \mathrm{~s}$ before LS insertion, but cleared the bit 0.1333 seconds late.

The report also demonstrates how PMU timing errors occurring around the leap second could also manifest as phase errors if the power system frequency is not exactly nominal. There is significant interest to ensure that the PMUs' UTC time remains at all times aligned to UTC in order to maintain the industry's measurement uncertainty tolerance of one percent Total Vector Error (TVE). Table 10 summarizes all the PMU responses to the leap second.

Table 10: Summary of PMU response to leap second

\begin{tabular}{|l|l|l|l|l|l|l|l|l|}
\hline PMU ID & $\mathbf{1}$ & $\mathbf{2}$ & $\mathbf{3}$ & $\mathbf{4}$ & $\mathbf{5}$ & $\mathbf{6}$ & $\mathbf{7}$ & $\mathbf{8}$ \\
\hline $\begin{array}{l}\text { Total period of time the SOC was not synchronized with } \\
\text { UTC }\end{array}$ & $17.000 \mathrm{~s}$ & $47.000 \mathrm{~s}$ & $4.000 \mathrm{~s}$ & $0.150 \mathrm{~s}$ & $1.933 \mathrm{~s}$ & $4.000 \mathrm{~s}$ & $2.000 \mathrm{~s}$ & 3.000 \\
\hline Pending bit was set at all & no & no & yes & yes & no & no & no & yes \\
\hline Pending bit was set and cleared at the correct time & no & no & no & no & no & no & no & no \\
\hline Occurred bit was set at all & no & no & yes & yes & no & no & no & yes \\
\hline Occurred bit was set and cleared at the correct time & no & no & no & no & no & no & no & no \\
\hline $\begin{array}{l}\text { Number of seconds of TOD for which there were less the } \\
\text { proper number of reports }\end{array}$ & 1 & 1 & many ${ }^{\dagger \dagger}$ & 1 & 1 & 1 \\
\hline $\begin{array}{l}\text { Number of seconds of TOD for which there was more } \\
\text { than the proper number of reports }\end{array}$ & 1 & 1 & 1 & 1 & 1 & 1 & 1 \\
\hline
\end{tabular}

$\dagger$ PMU ID 8 was not synchronized with UTC for 1 second beginning 59 seconds before leap second and for 2 seconds immediately following leap second.

$\dagger$ PMU ID 3 Beginning at the leap second and continuing at the time of writing, PMU ID 3 has sporadic periods where there are only 46 reports during a second. 14 reports are missing during these seconds.

\section{Acknowledgements}

The authors would like to thank Dr. Eugene Song, Gerard Stenbakken, and Dan Dwyer for their assistance in the laboratory and review of the draft report. Thank you to Gerald Fitzpatrick and Dr. Norma Goldstein for editing the draft report. Thank you to Nick Zielinski, NIST Summer Undergraduate Research Fellow, for assistance in programming the data analysis software.

This investigation was funded in part with support from the U.S. Department of Energy Office of Electricity Delivery and Energy Reliability Interagency Agreement DE-OE0000645, Philip N. Overholt, Program Officer; David Ortiz, Deputy Assistant Secretary, Energy Infrastructure Modeling and Analysis. 


\section{Annex A References}

[1] IEEE PES PSRC WG11, "IEEE Std. 1344(TM)," IEEE, Piscataway, NJ, 1995 (revised 2001).

[2] U.S. Army Range Commanders Council Inter Range Instrumentation Group, IRIG 200-04: Serial Time Code Formats, U.S. Army White Sands Missile Range: Range Commanders Council, 2004.

[3] IEEE PES PSRC WG11, IEEE Std. C37.118.2(TM)-2011, Piscataway, NJ: IEEE, 2011.

[4] IEEE PES PSRC WG 11, IEEE Std. C37.118(TM)-2005, Piscataway, NJ: IEEE, 2005. 